\title{
Intravenous immunoglobulin therapy in vasculitic ulcers: a case of polyarteritis nodosa
}

\author{
Petra M. Pego • Inês Aguiar Câmara • \\ José Pedro Andrade · João Matos Costa
}

Received: 3 November 2012/ Accepted: 21 January 2013/Published online: 27 February 2013

(C) Springer-Verlag Italia 2013

\begin{abstract}
Introduction Polyarteritis nodosa (PAN) is a systemic necrotizing medium-size-vessel vasculitis with variable clinical manifestations. Diagnosis is confirmed by histology or angiography. The mainstay of treatment is corticosteroids alone or combined with cyclophosphamide (CYF).

Case report Seventy-one-year-old female, follow-up started in 1997 at the age of 56 for suspected relapsing febrile viral exanthema. Skin biopsy was performed and the diagnosis of lymphomatoid papulosis was made, with complete response to treatment with dapsone. In 2005, she presented with arthralgia, lower limb (LL) edema, livedo reticularis and elevated erythrocyte sedimentation rate (ESR). PAN was confirmed on histology and visceral angiography; antineutrophil cytoplasmic antibodies (ANCA) were negative. She responded to prednisolone but relapsed in 2006. Twelve cycles of CYF were administered, with clinical, angiographic and analytical improvement. In 2008, a new relapse occured with LL neuropathic pain and ESR elevation. Electromyogram (EMG) confirmed axonal sensory polyneuropathy (PNP). Azathioprine was started with a poor response. A second EMG, 12 months later in 2009 still evidenced PNP, and nerve biopsy confirmed vasculitic neuropathy. In 2010, she had ulcers in LL and iron-deficient anemia. She started intravenous immunoglobulin (IVIG) for six cycles, achieving ulcer healing, absence of pain, no anemia and ESR normalization.
\end{abstract}

P. M. Pego $(\bowtie) \cdot$ I. A. Câmara · J. P. Andrade · J. M. Costa 3rd Department of Internal Medicine, Hospital Distrital de Santarém, 2005-177 Santarém, Portugal

e-mail: petrapego@gmail.com
Discussion IVIG therapy has proven benefit in Kawasaki disease, also showing efficacy in refractory ANCA-associated vasculitis. In PAN, only very few case reports show benefit. In this case, IVIG therapy induced total remission of LL ulcers and PNP, suggesting that it may be useful in selected cases of refractory PAN.

Keywords IVIG $\cdot$ Vasculitic ulcers $\cdot$ Polyarteritis nodosa Polyneuropathy

\section{Introduction}

Polyarteritis nodosa (PAN) is a systemic necrotizing vasculitis that typically affects medium-sized vessels. It is primary in the majority of cases, but may also be secondary to viral infections for instance, mostly hepatitis B virus [1,2].

It may present with several constitutional and organspecific clinical manifestations but has a tendency to spare the lungs [1].

The diagnosis requires a high level of clinical suspicion due to its variable clinical manifestations and should be confirmed by histology or angiography. It is typically not associated with antineutrophil cytoplasmic antibodies (ANCA) [2-4].

The mainstay of treatment is corticosteroids either alone or combined with cyclophosphamide [5-8].

\section{Case report}

A woman, born in 1941, with no previous relevant clinical conditions until the age of 56, initiated follow-up at the Dermatology Clinic in October 1997 for a suspected febrile viral exanthema. Viral serologies were negative for acute 
infection (Table 1). She improved with symptomatic treatment and topical therapy. However, symptoms relapsed and a skin biopsy was performed, suggesting the diagnosis of lymphomatoid papulosis. Treatment with dapsone was then started with complete remission.

In January 2005, she presented with livedo reticularis, cutaneous nodules, lower limb edema, fever and arthralgias. Erythrocyte sedimentation rate (ESR) was elevated (100 mm/h) (Fig. 1). Autoantibodies, including p-ANCA and c-ANCA, were negative (Table 2). Lower limb arterial and venous Doppler were also normal. A new skin biopsy was then performed and showed non-granulomatous lymphocytic vasculitis. Abdominal angiography revealed microaneurysms very typical of PAN, thus confirming the diagnosis. She initiated treatment with prednisolone (40 mg/day) with good response.

In March 2006, symptoms relapsed while tapering prednisolone. She initiated follow-up at Autoimmune Disease Clinic and started treatment with intravenous cyclophosphamide $\left(750 \mathrm{mg} / \mathrm{m}^{2}\right.$ monthly for 6 months and afterwards every 3 months) completing 12 cycles (associated with prednisolone-60 mg/day initially, with further tapering reaching $10 \mathrm{mg} /$ day). There was clinical improvement and normalization of ESR. She also repeated abdominal angiography by the end of treatment which was then normal.

Table 1 Viral serologies in October 1997

\begin{tabular}{ll}
\hline Hepatitis B virus & Negative \\
Hepatitis C virus & Negative \\
Mono test & Negative \\
Epstein Barr virus & IgG+ \\
Cytomegalovirus & Negative \\
Herpes Simplex virus 1 and 2 & IgG+ \\
Parvovirus B19 & IgG+ \\
Echovirus & IgG+ \\
Adenovirus & IgG+ \\
Coxsackie A virus & Negative \\
Coxsackie B virus & IgG+ \\
\hline
\end{tabular}

In September 2008, a new cutaneous relapse occurred, associated with neuropathic pain in lower limbs. ESR was once again elevated. Electromyogram (EMG) revealed axonal sensitive polyneuropathy. She initiated treatment with azathioprine $(0.9 \mathrm{mg} / \mathrm{kg} /$ day initially, increasing progressively until $2.7 \mathrm{mg} / \mathrm{kg} /$ day), maintaining prednisolone simultaneously. There was only a mild improvement. By 2009, symptoms persisted and ESR was increasing. The EMG still showed axonal sensitive polyneuropathy, without any improvement. Therefore, a nerve biopsy was performed that confirmed the vasculitic nature of neuropathy.

In September 2010, she presented with ulcers in lower limbs (Fig. 2a). ESR was still rising and she developed an iron-deficient anemia, gastroscopy and colonoscopy were both normal. In November 2010, she started treatment with intravenous immunoglobulin (IVIG) completing six cycles ( $2 \mathrm{~g} / \mathrm{kg}$ in each cycle), while maintaining treatment with prednisolone and azathioprine (150 mg/day). There was clinical improvement after the second cycle (Fig. 2b), achieving, by the end of treatment (May 2011), complete ulcer healing, absence of pain, no anemia and ESR normalization. In November 2011, she maintained remission (Fig. 2c) with normal hemoglobin and ESR; at her last

Table 2 Autoimmunity testing results during follow-up

\begin{tabular}{lllll}
\hline & 2005 & 2008 & 2011 & 2012 \\
\hline c-ANCA & Negative & Negative & Negative & Negative \\
p-ANCA & Negative & Negative & Negative & Negative \\
ANA & Negative & Negative & Negative & Negative \\
Anti-dsDNA & Negative & Negative & Negative & \\
Anti-SSA & & Negative & Negative & \\
Anti-SSB & & Negative & Negative & \\
Anti-Sm & & & Negative & \\
Anti-RNP & & Negative & Negative & \\
Anticardiolipin & Negative & Negative & Negative & \\
antibody & & & & \\
Anti-B2GPI & Negative & Negative & Negative & \\
Circulating & & & Negative & \\
Imunocomplexes & & & & \\
Anti-Rib-P & & Negative & Negative & \\
Cryoglobulins & & & Negative & \\
\hline
\end{tabular}

Fig. 1 Erythrocyte sedimentation rate $(E S R)$ and hemoglobin $(H b)$ values since January 2005 until July 2012

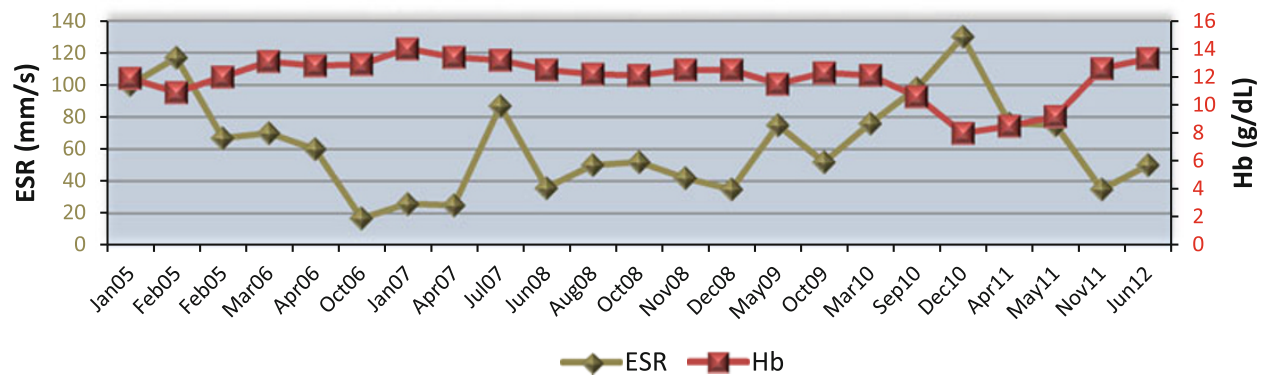


Fig. 2 Patient's lower limb in a September 2010, b January 2011 and c November 2011
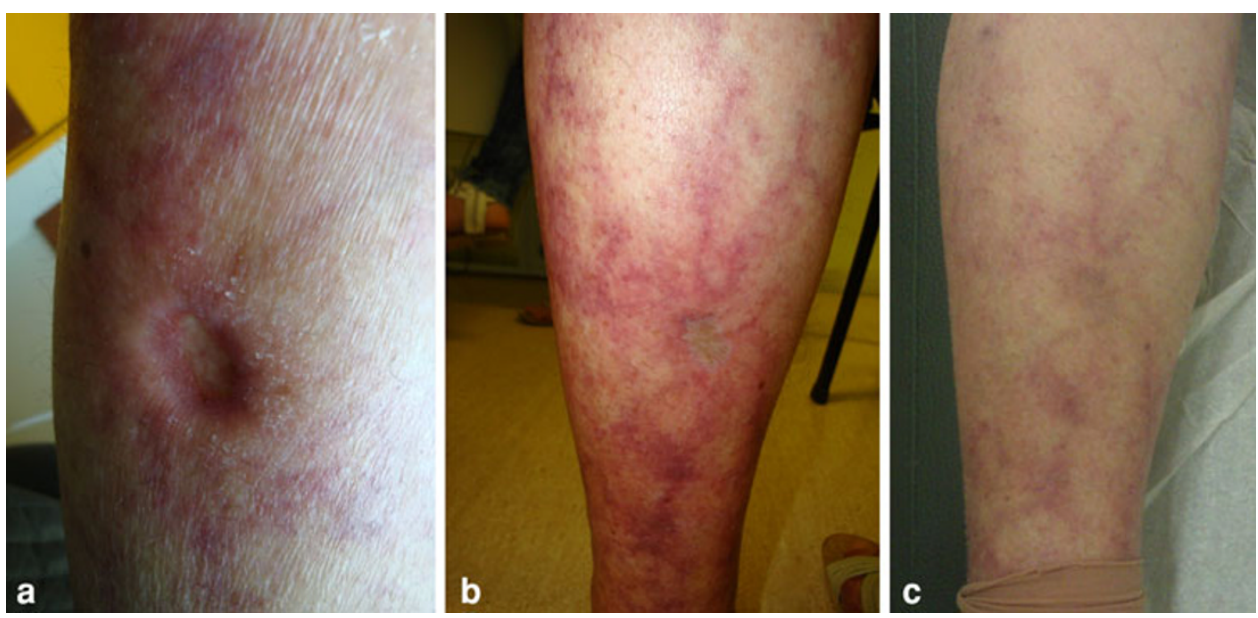

appointment, in June 2012, she was still in clinical remission despite a small rise in ESR (treated with azathioprine $150 \mathrm{mg} /$ day, without prednisolone since December 2011). Autoantibodies, including p-ANCA and c-ANCA, were tested once again in 2012, and were negative.

\section{Discussion}

IVIG is a therapy with a complex mode of action which is not yet fully understood. It was initially used as replacement therapy in primary and secondary immunodeficiencies. More recently its use has been extended to several other clinical conditions such as infectious diseases, neuroimmunological diseases and systemic autoimmune diseases [9].

In particular, IVIG has shown benefit in several types of vasculitis.

There is evidence for IVIG use in Kawasaki disease [10, 11], suggesting a significant reduction in new coronary artery aneurysms. The benefit of IVIG in antineutrophil cytoplasmic antibody-associated vasculitis has been shown in one placebo-controlled [12] and in several open-label studies [13-24]. Most of those studies demonstrated a reduction in disease activity after failure of standard therapy with corticosteroids and immunosuppressants in patients with Wegener's granulomatosis or microscopic polyangiitis. In other vasculitis, evidence of benefit is limited to isolated case reports [9].

In PAN there are, to our knowledge, only 14 cases [2536] in the literature showing benefit of IVIG, although sometimes only temporary [25-27]. Among those 13 cases, 4 [28-31] were children, 2 were Parvovirus B19-associated PAN [32] and 1 [33] Hepatitis B-associated PAN. Only one of those case reports was ulcer healing as in the case described above [34].

There are also case reports illustrating benefit of IVIG, particularly in vasculitic peripheral neuropathy in several clinical conditions unresponsive to conventional treatment [37-40].

In the case described we present a patient with the diagnosis of PAN confirmed by visceral angiography which showed microaneurysms that are very typical features of PAN. Repeated ANCA negativity also supports this diagnosis and, together with the absence of renal or lung involvement, makes the alternate diagnosis of microscopic polyangiitis less likely at the moment.

The choice of treatment with intravenous immunoglobulin in this patient was based mainly on the failure of conventional treatment along with the presence of polyneuropathy of documented vasculitic nature [37-40]. The lower limb ulcers were also assumed to be secondary to vasculitis. The treatment resulted in total remission of all clinical and analytical manifestations, including not only absence of previously debilitating neuropathic pain but also ulcer healing. The iron-deficient anemia was also completely normalized, posing the hypothesis, it could be related with PAN as well.

At her last appointment she was still without any symptom, despite a new small rise in ESR, so there has been no relapse so far.

The case presented illustrates IVIG may be beneficial in selected cases of refractory PAN, including those presenting with vasculitic ulcers.

Conflict of interest Petra M. Pego, Inês Aguiar Câmara, José Pedro Andrade, João Matos Costa declare that they have no conflict of interest.

Informed Consent All procedures followed were in accordance with the ethical standards of the responsible committee on human experimentation (institutional and national) and with the Helsinki Declaration of 1975, as revised in 2008. Informed consent was obtained from all patients for being included in the study.

Animal studies No animal studies were carried out by the authors for this article. 


\section{References}

1. Colmegna I, Maldonado-Cocco JA (2005) Polyarteritis nodosa revisited. Curr Rheumatol Rep 7(4):288-296

2. Guillevin L, Pagnoux C, Teixeira L (2008) Polyarteritis nodosa. In: Ball GV, Bridges SL (eds) Vasculitis, 2nd edn. Oxford University Press, Oxford, pp 335-353

3. Hughes LB, Bridges SL Jr (2002) Polyarteritis nodosa and microscopic polyangiitis: etiologic and diagnostic considerations. Curr Rheumatol Rep 4(1):75-82

4. Henegar C, Pagnoux C, Puéchal X, Zucker JD, Bar-Hen A, Le Guern V, Saba M, Bagnères D, Meyer O, Guillevin L, French Vasculitis Study Group (2008) A paradigm of diagnostic criteria for polyarteritis nodosa: analysis of a series of 949 patients with vasculitides. Arthritis Rheum 58(5):1528-1538

5. de Menthon M, Mahr A (2011) Treating polyarteritis nodosa: current state of the art. Clin Exp Rheumatol 29(1 Suppl 64): S110-S116

6. Ribi C, Cohen P, Pagnoux C, Mahr A, Arène JP, Puéchal X, Carli P, Kyndt X, Le Hello C, Letellier P, Cordier JF, Guillevin L, French Vasculitis Study Group (2010) Treatment of polyarteritis nodosa and microscopic polyangiitis without poor-prognosis factors: a prospective randomized study of one hundred twentyfour patients. Arthritis Rheum 62(4):1186-1197

7. Guillevin L, Cohen P, Mahr A, Arène JP, Mouthon L, Puéchal X, Pertuiset E, Gilson B, Hamidou M, Lanoux P, Bruet A, Ruivard M, Vanhille P, Cordier JF (2003) Treatment of polyarteritis nodosa and microscopic polyangiitis with poor prognosis factors: a prospective trial comparing glucocorticoids and six or twelve cyclophosphamide pulses in sixty-five patients. Arthritis Rheum 49(1):93-100

8. Mukhtyar C, Guillevin L, Cid MC, Dasgupta B, de Groot K, Gross W, Hauser T, Hellmich B, Jayne D, Kallenberg CG, Merkel PA, Raspe H, Salvarani C, Scott DG, Stegeman C, Watts R, Westman K, Witter J, Yazici H, Luqmani R, European Vasculitis Study Group (2009) EULAR recommendations for the management of primary small and medium vessel vasculitis. Ann Rheum Dis 68(3):310-317

9. Aries PM, Hellmich B, Gross WL (2005) Intravenous immunoglobulin therapy in vasculitis: speculation or evidence? Clin Rev Allergy Immunol 29(3):237-245

10. Vaitla PM, McDermott EM (2010) The role of high-dose intravenous immunoglobulin in rheumatology. Rheumatology 49(6): 1040-1048

11. Oates-Whitehead RM, Baumer JH, Haines L, Love S, Maconochie IK, Gupta A, Roman K, Dua JS, Flynn I (2003) Intravenous immunoglobulin for the treatment of Kawasaki disease in children. Cochrane Database Syst Rev 4:CD004000

12. Jayne DR, Chapel H, Adu D, Misbah S, O'Donoghue D, Scott D, Lockwood CM (2000) Intravenous immunoglobulin for ANCAassociated systemic vasculitis with persistent disease activity. QJM 93(7):433-439

13. Jayne DR, Davies MJ, Fox CJ, Black CM, Lockwood CM (1991) Treatment of systemic vasculitis with pooled intravenous immunoglobulin. Lancet 337(8750):1137-1139

14. Tuso P, Moudgil A, Hay J, Goodman D, Kamil E, Koyyana R, Jordan SC (1992) Treatment of antineutrophil cytoplasmic autoantibody-positive systemic vasculitis and glomerulonephritis with pooled intravenous gammaglobulin. Am J Kidney Dis 20(5): 504-508

15. Richter C, Schnabel A, Csernok E, Reinhold-Keller E, Gross WL (1993) Treatment of Wegener's granulomatosis with intravenous immunoglobulin. Adv Exp Med Biol 336:487-489

16. Martinez V, Cohen P, Pagnoux C, Vinzio S, Mahr A, Mouthon L, Sailler L, Delaunay C, Sadoun A, Guillevin L, French Vasculitis
Study Group (2008) Intravenous immunoglobulin for relapses of systemic vasculitides associated with antineutrophil cytoplasmic antibodies: results of a multicenter, prospective, open-label study of twenty-two patients. Arthritis Rheum 58(1):308-317

17. Langford CA, Hoffman GS (2008) Intravenous immunoglobulin in Wegener's granulomatosis and microscopic polyangiitis. Arthritis Rheum 58(7):2211-2212

18. Jayne DR, Lockwood CM (1996) Intravenous immunoglobulin as sole therapy for systemic vasculitis. Br J Rheumatol 35(11):1150-1153

19. Jayne DR, Esnault VL, Lockwood CM (1993) ANCA anti-idiotype antibodies and the treatment of systemic vasculitis with intravenous immunoglobulin. J Autoimmun 6(2):207-219

20. Richter C, Schnabel A, Csernok E, De Groot K, Reinhold-Keller E, Gross WL (1995) Treatment of anti-neutrophil cytoplasmic antibody (ANCA)-associated systemic vasculitis with high-dose intravenous immunoglobulin. Clin Exp Immunol 101(1):2-7

21. Levy Y, Sherer Y, George J, Langevitz P, Ahmed A, Bar-Dayan Y, Fabbrizzi F, Terryberry J, Peter J, Shoenfeld Y (1999) Serological and clinical response to treatment of systemic vasculitis and associated autoimmune disease with intravenous immunoglobulin. Int Arch Allergy Immunol 119(3):231-238

22. Hamilos DL, Christensen J (1991) Treatment of Churg-Strauss syndrome with high dose intravenous immunoglobulin. J Allergy Clin Immunol 88(5):823-824

23. Tsurikisawa N, Taniguchi M, Saito H, Himeno H, Ishibashi A, Suzuki S, Akiyama K (2004) Treatment of Churg-Strauss syndrome with high dose intravenous immunoglobulin. Ann Allergy Asthma Immunol 92(1):80-87

24. Danieli MG, Cappelli M, Malcangi G, Logullo F, Salvi A, Danieli G (2004) Longterm effectiveness of intravenous immunoglobulin in Churg-Strauss syndrome. Ann Rheum Dis 63(12):1649-1654

25. Asano Y, Ihn H, Maekawa T, Kaono T, Tamaki K (2006) High dose intravenous immuglobulin infusion in polyarteritis nodosa: report of one case and review of the literature. Clin Rheumatol 25(3):396-398

26. Machet L, Vincent O, Machet MC, Barruet K, Vaillant L, Lorette G (1995) Cutaneous periarteritis nodosa resistant to combined corticosteroids and immunosuppressive agents. Efficacy of treatment with intravenous immunoglobulins. Ann Dermatol Venereol 122(11-12):769-772

27. Kroiss M, Hohenleutner U, Gruss C, Glaessl A, Landthaler M, Stolz W (2001) Transient and parcial effect of high-dose intravenous immunoglobulin in polyarteritis nodosa. Dermatology 203(2):188-189

28. Girisgen I, Sonmez F, Koseoglu K, Erisen S, Yllmaz D (2012) Polyarteritis nodosa and Henoch-Schönlein purpura nephritis in a child with Familial Mediterranean fever: a case report. Rheumatol Int 32(2):529-533

29. González-Fernández MA, García-Consuegra J (2007) Polyarteritis nodosa resistant to conventional treatment in a pediatric patient. Ann Pharmacother 41(5):885-890

30. Uziel Y, Silverman ED (1998) Intravenous immunoglobulin therapy in a child with cutaneous polyarteritis nodosa. Clin Exp Rheumatol 16(2):187-189

31. Drymalski W, Hosen RS, Smook S (1994) Response to pooled gamma globulin therapy in a child with polyarteritis nodosa. Arch Pediatr Adolesc Med 148(5):543-544

32. Finkel TH, Török TJ, Ferguson PJ, Durigon EL, Zaki SR, Leung DY, Harbeck RJ, Gelfand EW, Saulsbury FT, Hollister JR et al (1994) Chronic parvovirus B19 infection and systemic necrotising vasculitis: opportunistic infection or aetiological agent? Lancet 343(8908):1255-1258

33. Boman S, Balen JL, Seggey JS (1995) Dramatic responses to intravenous immunoglobulin in vasculitis. J Intern Med 238(4): $375-377$ 
34. Lobo I, Ferreira M, Silva E, Alves R, Selores M (2008) Cutaneous polyarteritis nodosa treated with intravenous immunoglobulins. J Eur Acad Dermatol Venereol 22(7):880882

35. Balbir-Gurman A, Nahir AM, Braun-Moscovici Y (2007) Intravenous immunoglobulins in polyarteritis nodosa restricted to the limbs: case reports and review of the literature. Clin Exp Rheumatol 25(1 Supp 144):S28-S30

36. Wagner AD, Feist T, Prondzinsky R, Fleig WE, Keysser G (2001) Joint and muscle pain with mononeuritis multiplex, tetraparesis, and myocardial infarction in a previously healthy adult. Ann Rheum Dis 60(11):1003-1006
37. Levy Y, Uziel Y, Zandman G, Rotman P, Amital H, Sherer Y, Langevitz P, Goldman B, Shoenfeld Y (2005) Response of vasculitic peripheral neuropathy to intravenous immunoglobulin. Ann N Y Acad Sci 1051:779-786

38. Gorson KC (2007) Vasculitic neuropathies: an update. Neurologist 13(1):12-19

39. Burns TM, Schaublin GA, Dyck PJB (2007) Vasculitic neuropathies. Neurol Clin 25(1):89-113

40. Levy Y, Uziel Y, Zandman GG, Amital H, Sherer Y, Langevitz P, Goldman B, Shoenfeld Y (2003) Intravenous immunoglobulins in peripheral neuropathy associated with vasculitis. Ann Rheum Dis 62(11):1221-1223 